\title{
Costello syndrome
}

INSERM

\section{Source}

INSERM. (1999). Orphanet: an online rare disease and orphan drug data base. Costello syndrome. ORPHA:3071

Costello syndrome (CS) is a rare multisystemic disorder characterized by failure to thrive, short stature, developmental delay or intellectual disability, joint laxity, soft skin, and distinctive facial features. Cardiac and neurological involvement is common and there is an increased lifetime risk of certain tumors. 